\title{
O Pantanal por elas: o trabalho da mulher pantaneira no turismo
}

\author{
The Pantanal for them: the work of pantaneira women in tourism \\ El Pantanal por ellas: el trabajo de las mujeres pantaneira en el turismo
}

Julio Francisco Alves Fernandes

ONG Wetlands International, Brasil

juliofeernandes@gmail.com

Ana Paula Correia de Araújo

Universidade Federal de Mato Grosso do Sul (UFMS),

Brasil

anapaula_rj@yahoo.com

Mara Aline Ribeiro

Universidade Federal de Mato Grosso do Sul(UFMS),

Brasil

mara_aline@yahoo.com.br
DOI: https://doi.org/10.18472/cvt.21n1.2021.1833

Redalyc: http://www.redalyc.org/articulo.oa?

$\mathrm{id}=115466307002$

Recepción: 24 Junio 2020

Aprobación: 04 Febrero 2021

\section{Resumo:}

O papel da mulher é fundamental para revelar novas territorialidades em uma região rural complexa social e ambientalmente como o Pantanal, onde a produção do espaço inicialmente aconteceu a partir da pecuária de corte, a qual, no final do século passado passou a ser compartilhado com a atividade turística. Nesse universo, a mulher pantaneira ocupa uma posição de destaque, mostrando-se integrada ao mundo do trabalho construído no país como um todo. Mesmo assim, em geral é pouco qualificada, mal remunerada e as atividades desenvolvidas representam a extensão do trabalho doméstico. Entretanto, é através do trabalho que o empoderamento ocorre, seja pela valorização da renda no âmbito familiar, ou pela afirmação identitária. Esse artigo discute os meandros do viver pantaneiro a partir da mulher, e tem como objetivo central é analisar o papel da mulher na produção do espaço turístico pantaneiro. O recorte espacial da pesquisa é a comunidade ribeirinha do Passo da Lontra, sub-região do Pantanal do Abobral, município de Corumbá (MS). A metodologia contou com revisão bibliográfica e trabalho de campo, com entrevistas estruturadas e semiestruturadas, analisadas à luz da geografia.

Palavras-CHave: Pantanal, Mulheres, Turismo, Trabalho..

\section{Abstract:}

The role of women is fundamental to show new territorialities in a rural region, its social and environmental complexity, as is the case of the Pantanal, where the production of the space happened initially with beef cattle, which, at the end of the last century began to be shared with the tourist activity. In this universe, the Pantanal woman stands out. Even so, in general, she is poorly qualified, earns very little and the activities developed are restricted to domestic work. However, it is through work that empowerment takes place, whether through family income, or through identity affirmation. This article discusses the way of life in the Pantanal based on women, and its main objective is to analyze the role of women in the production system of the Pantanal tourism space. The spatial focus of the research is the riverside community of Passo da Lontra, sub-region of the Pantanal do Abobral, municipality of Corumbá (MS). The methodology had bibliographic review and fieldwork, with structured and semistructured interviews, analyzed by the geographic sciences method.

KeYworDs: Pantanal, Women, Turism, Work.

\section{Resumen:}

El papel de la mujer es esencial para resaltar las nuevas territorialidades en una región rural con su complejidad social y ambiental, como es el caso del Pantanal, donde la producción del espacio ocurrió inicialmente con ganado vacuno, que, a fines de siglo pasado comenzó a ser compartido con la actividad turística. En este universo, la mujer Pantanal se destaca. Aun así, en general, está poco calificada, gana muy poco y las actividades desarrolladas se limitan al trabajo doméstico. Sin embargo, es a través del trabajo que 
se potencia el empoderamiento, incluso aumentando el ingreso familiar o afirmando la identidad. Este artículo analiza la vida en el Pantanal desde la perspectiva de la mujer, y su objetivo principal es analizar el papel de la mujer en la producción del espacio turístico del Pantanal. El foco espacial de la investigación es la comunidad ribereña de Passo da Lontra, subregión del Pantanal do Abobral, municipio de Corumbá (MS). La metodología empleó la revisión bibliográfica y el trabajo de campo, con entrevistas estructuradas y semiestructuradas, analizadas por la ciencia geográfica.

Palabras Clave: Pantanal, Mujer, Turismo, Trabajo.

\section{INTRODUÇÃO}

Localizado no centro da América do Sul, com aproximadamente $150.000 \mathrm{~km}^{2}$ (Instituto Brasileiro de Geografia e Estatística [IBGE], 2020), o Pantanal caracteriza-se por ser uma região que se expande por diferentes territórios. No Brasil, ocupa terras nos estados de Mato Grosso e Mato Grosso do Sul, na região Centro-Oeste e se estende pela Bolívia (18\%) e Paraguai (4\%). A planície pantaneira tem a nascente do principal rio, o Paraguai, no estado do Mato Grosso e é na porção oeste de Mato Grosso do Sul que a junção com os contribuintes e vários outros fatores físicos, como a baixa declividade, vão contribuir para a dinâmica de inundação.

Entre cheias e vazantes, turismo e pecuária, este artigo discute o papel da mulher pantaneira, com ênfase na socioeconomia e na transformação da identidade socioterritorial, itens que Biasoli-Alves (2000) julga necessários a qualquer estudo de gênero com intuito de analisar, verdadeiramente, o aumento da presença feminina nos diferentes aspectos da sociedade, tais como: a importância do trabalho feminino no espaço rural, os anseios e aspirações, as relações interpessoais e de sexo, a percepção da vida e do trabalho, enfim, os papéis exercidos que representam os elementos centrais de análise e condução da pesquisa.

Para tanto, o objetivo central é analisar o papel da mulher na produção do espaço turístico pantaneiro. A metodologia baseia-se no processo de aproximação com o objeto de estudo por intermédio da observação participante, com entrevistas estruturadas e semiestruturadas, aplicação de questionários, registros fotográficos do cotidiano social e econômico das mulheres do Pantanal, ambos analisados à luz da ciência geográfica.

Os estudos de gênero, turismo e divisão do trabalho têm despertado interesse de pesquisadores/as das mais diferentes áreas, tais como, o turismo, a sociologia, a antropologia, a geografia, a economia, a história, dentre outras; as quais consideram como fundamental para o desenvolvimento da atividade turística a compreensão do trabalho da mulher como primordial na produção do espaço para o turismo.

A delimitação espacial do estudo é uma localidade no município de Corumbá, no estado de Mato Grosso do Sul denominada Passo da Lontra, instalada nos arredores da ponte sobre o rio Miranda, às margens da Estrada Parque Pantanal e a 9 km do posto da Polícia Militar Ambiental Buraco das Piranhas na BR-262, na sub-região do Pantanal do Abobral. A opção por essa comunidade ribeirinha como área de estudo se deu por dois motivos principais: a acessibilidade via Estrada-parque Pantanal e a dinâmica social e econômica originária, nos dias atuais, sobretudo pela atividade turística.

\subsection{Entrando no Pantanal...}

O ritmo marcado pelas cheias e vazantes caracterizam a maior planície alagável contínua do mundo, o Pantanal (Tomas et al. 2019). Tais especificidades aliadas à topografia dificultam o acesso à região que, desde a colonização (portuguesa e espanhola), as missões jesuíticas, as incursões dos bandeirantes paulistas e durante toda a trajetória no espaço-tempo, concentrou a ocupação nas bordas e partes mais secas (Esselin, 2012; Ribeiro, 2015). 
A economia local, inicialmente, se estruturou a partir da pecuária de corte, com mão de obra sobremaneira masculina e, a partir da segunda metade do século passado, começou a dividir o espaço com a atividade turística, quando, efetivamente, o trabalho e o protagonismo feminino se apresentam no Pantanal.

Apesar de ser uma região bem definida, o Pantanal apresenta 11 subdivisões internas, (Figura 1), definidas a partir das características hidro-geomorfológicas, das vegetações e dos períodos de alagamento. São elas: Paiaguás, Nhecolândia, Paraguai, Nabileque, Porto Murtinho, Abobral, Miranda, Aquidauana, no Mato Grosso do Sul, e Cáceres, Poconé e Barão do Melgaço, no Mato Grosso, de acordo com Silva e Abdon (1998).

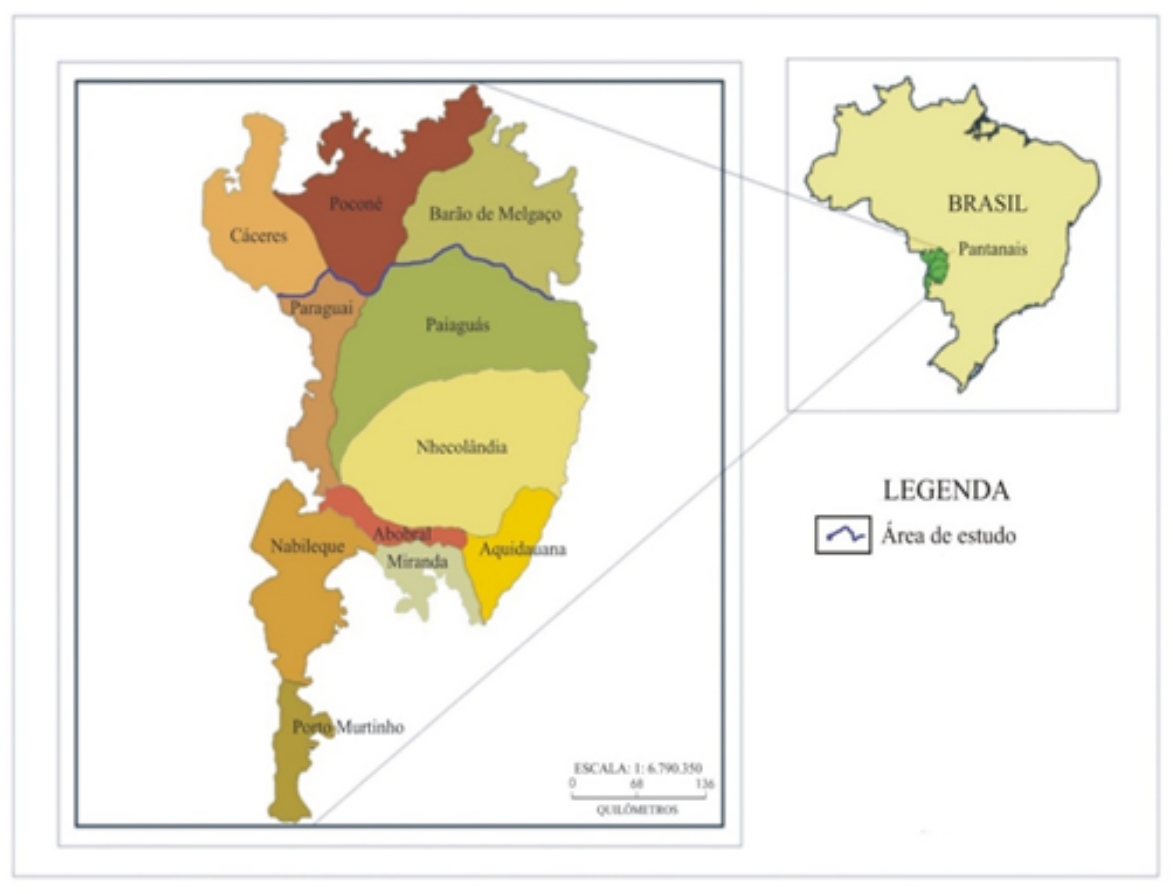

Figura 1: Pantanal, sub-regiões internas. Araújo, A. (2006).

O viver pantaneiro é eminentemente rural e se baseia nas tradições da pecuária bovina de corte, desenvolvida há mais de duzentos anos na região. A bovinocultura tornou-se a principal atividade econômica, responsável pelo desbravamento e ocupação do Pantanal (Araújo, 2006). O trabalho com o gado é executado, quase que exclusivamente, por homens, em um modelo secular de produção extensiva. Essa característica imprime na paisagem grandes propriedades, distantes entre si, e reduzida população, com uma identidade masculina que carrega o imaginário da força, da coragem e da bravura.

Conforme Araújo e Bicalho (2010), os anos de 1990 marcam dois processos distintos, porém integrados, de alteração na organização espacial existente. De um lado, observa-se a modernização e a diversificação dos sistemas produtivos de pecuária de corte, com a introdução de sistemas sustentáveis, inclusive. E, de outro, a expansão da atividade turística no espaço rural pantaneiro, nas modalidades de turismo de pesca, contemplação, rural e cultural.

O turismo foi inserido, timidamente, no Pantanal, desde os anos 70 do século passado. Entretanto, a partir da década de 1990, a atividade é intensificada e se percebe o esforço de construção do espaço turístico no rural regional e de ofertar um produto turístico de qualidade, baseado na exuberância pantaneira e nas tradições da pecuária. A condução desse processo, inicialmente, foi feita por pecuaristas pantaneiros tradicionais que transformaram suas propriedades em fazendas-hotéis (Araújo, 2006). A partir daí, a gestão e a gerência da atividade passam a ser compartilhadas entre homens e mulheres, as fazendas se tornam multifuncionais, com uma divisão do trabalho mais ampla: os homens, na pecuária e no turismo; e as mulheres, mais especificamente, no turismo. 
Além da administração, observa-se a participação efetiva da "mulher pantaneira[1]" em todas as atividades necessárias ao funcionamento e desenvolvimento do negócio turístico. Com isso, passam a assumir um papel de destaque na economia regional, a despeito dessas ações não serem reveladas explicitamente. Nesse movimento, as relações de gênero, ainda que mantendo as marcas do patriarcado e, em consequência, a relação de autoridade-dependência, começam a demonstrar pequenas rupturas, transformando a paisagem e, com ela, a força do papel da mulher - historicamente negligenciado - no Pantanal, se revela.

O processo de desenvolvimento, do Passo da Lontra (área de estudo do artigo) pode ser observado a partir da primeira metade do século passado como um pequeno entreposto comercial para atender, sobretudo, as pessoas envolvidas no trabalho com a pecuária de corte no Pantanal do Abobral (figura 01). Atualmente a dinâmica local gira em torno do turismo e dos elementos que o compõem, tanto que no entorno da localidade estão instaladas pousadas, pesqueiros, barcos-hotéis e campings, fazendo do turismo a principal atividade econômica das quase 30 famílias que ali vivem, dentre elas, uma parte representativa tem na mão de obra feminina a única fonte provedora da família.

Como a organização do território capitalista é marcada por diferenças espaço-temporais, dentro da lógica do desenvolvimento desigual e combinado via divisão e especialização de áreas, as mudanças no papel da mulher na família e na sociedade não acontecem de forma simultânea no espaço urbano e rural. Nesse sentido, o lugar da pesquisa é uma referência para a análise, considerando as transformaçóes pelas quais a localidade está passando com a inserção da atividade turística que alterou a vida das pessoas de forma mais intensa se comparada às demais sub-regiões.

\subsection{Procedimentos metodológicos}

A abordagem metodológica da pesquisa é exploratória analítica com elementos qualitativos e quantitativos analisados à luz da ciência geográfica em um contexto de gênero, do turismo e do rural em movimento. No decorrer de todo o processo científico a revisão bibliográfica foi uma constante, se adaptando a cada etapa da investigação, considerando, também, o referencial teórico dos/as autores/as locais e as especificidades do Pantanal.

As escutas sistemáticas a partir de entrevistas, questionários e conversas com as sujeitas da pesquisa, possibilitou a aproximação das autoras com o objeto de estudo, enquanto observadoras participantes.

O ato de observar é um dos meios mais frequentemente utilizados pelo ser humano para conhecer e compreender as pessoas, as coisas, os acontecimentos e as situações. Observar é aplicar os sentidos a fim de obter uma determinada informação sobre algum aspecto da realidade. É mediante o ato intelectual de observar o fenômeno estudado que se concebe uma noção real do ser ou ambiente natural, como fonte direta dos dados (Queiroz et al., 2007, p. 277).

Considerando a relevância do trabalho de campo em um estudo exploratório, optou-se por três etapas de imersão na delimitação espacial da pesquisa, a primeira de aproximação, com reuniões informais e identificação das mulheres que se manifestaram predispostas à responderem aos questionários. Passados cerca de 30 dias iniciou-se, efetivamente, a aplicação dos questionários e das entrevistas. Durante esse período, foram mantidos contatos pelas redes sociais para que a interação construída entre as pessoas envolvidas no levantamento de campo não se perdesse. A terceira parte foi para referendar a atividade, a partir das rodas de conversas e da análise do grupo de pesquisadores.

As informações de campo foram obtidas por meio de vinte e três entrevistas e o mesmo número de questionários, tendo como referência as categorias: idade, número de filhos e grau de escolaridade, elencadas por expressarem tecnicamente o delineamento das sujeitas da pesquisa, além de instigar sobre o sentido de 'ser pantaneira'. 
A tabulação dos dados coletados promoveu a elaboração de gráficos que oportunizaram a investigação quantitativa do objeto de estudo e asseguraram uma compreensão qualitativa, estruturada no perfil sociocultural das mulheres pantaneiras, porque

[...] os fatos sociais dificilmente podem ser tratados como coisas, pois são produzidos por seres que sentem, pensam, agem e reagem, sendo capazes, portanto, de orientar a situação de diferentes maneiras. Da mesma forma o pesquisador, pois ele é também um ator que sente, age e exerce sua influência sobre o que pesquisa (Gil, 2011, p. 05).

A interpretação do feminino no rural a partir da atividade turística, tendo como base o referencial teórico proposto, ressignifica o perfil socioeconômico e cultural das mulheres que vivem e produzem no Pantanal.

\subsection{O protagonismo da mulher do e no Pantanal}

Muitos autores revelam que a participação da mulher no mercado de trabalho não é um dado novo. "No final do século XIX, atividades de comércio e serviços eram predominantemente femininas" Hobsbawm (1995, p. 304). Entretanto, com as guerras na primeira metade do século $\mathrm{XX}$, as mulheres passam a exercer certo protagonismo no universo até então 'masculino' em função da realocação de mão de obra masculina para as frentes de batalha. Naquele momento, passam a ocupar os cargos que, na chamada postura convencional de estratificação de classes, estão ligados aos homens, porém, em condição de subalternidade (Giddens, 2005; Hobsbawm, 1995).

A visão da funcionalidade de protagonista familiar, tida como essencial, “[...] é acrescida a posição de provedora do sustento da família” (Parsons e Bales, 1956 como citado em Giddens, 2005, p.152). Em paralelo, as mulheres se unem na busca por igualdade de direitos civis, como o voto e a participação na vida política.

A realidade mostra uma estrutura da economia anterior desfazendo-se e, aos poucos, sendo substituída por outra, que passa a "exigir da mulher mais habilidades além das que já vêm de berço". Ela precisa, agora, ser capaz também de aprender a gerir salários (fazer contas) e a cuidar de que os filhos (homens, sobretudo) dominem as tarefas da escola [...]. Isto, não porque ela seja um sujeito de direitos e deva lhe ser assegurada a igualdade, mas porque se espera dela competências que melhor promovam a educação dos filhos e a própria vida doméstica, que façam dela o suporte adequado para o sucesso profissional de seu esposo (Biasoli-Alves, 2000, p. 236).

A partir da década de 1950, as conquistas ocorrem no quesito educação (Biasoli-Alves, 2000). Hobsbawm (1995, p. 305) "assevera que imediatamente após a Segunda Guerra Mundial as mulheres correspondiam a $20 \%$ da população universitária nos países centrais”.

O movimento feminista ressurge com força nos anos de 1960, revelando agora a necessidade de ruptura com os papéis convencionais a elas atribuídos. Superada a luta pelos direitos civis contidas nas manifestações do início do século XX, os enfrentamentos pelo direito ao desejo, ao controle do corpo e ao prazer são os ingredientes fundamentais de ressignificação do feminismo. Conforme Giddens (1993), as mulheres são a vanguarda da transformação da intimidade e a maneira como se percebem hoje é consequência direta do feminismo da segunda geração. Os avanços dos métodos contraceptivos, da educação e do trabalho somados à afirmação do desejo e do prazer alteram a identidade feminina.

A identidade não se restringe à questão: "quem nós somos", mas também "quem nós podemos nos tornar"; desse modo, a construção da identidade tem a ver com raízes (ser), mas também com rotas e rumos (tornar-se, vir a ser) (Araújo e Haesbaerth, 2007, p. 97).

Hall (2004) afirma que identidades são construídas a partir das raízes culturais (herança, memória, passado) e também a partir de mudanças e tendências sociais (futuro). "A identidade é sempre uma construção de significado e experiência definida a partir de atributos culturais que norteiam o processo de identificação e distinção do indivíduo ou de um grupo" (Castells, 1999, p. 22). 
"Como o mundo é uma representação" (Schopenhauer como citado em Maffessoli, 1995, p. 123), o universo é simbólico e relacional. A existência do "eu" só é permitida mediante o contato com o outro, com o existir social é a partir dessa relação dialética entre o "eu" e o "outro" (o grupo social) que as aspirações e desejos individuais e coletivos são construídos. Identidade e alteridade são partes indissociáveis do processo de transformação feminina.

Com aspirações próprias, as mulheres deixam de ser uma extensão do marido e da casa, e passam a existir na sua individualidade. Segundo Hobsbawm (1995, p. 307), "[...] são inegáveis os sinais de mudanças significativas, e até mesmo revolucionárias, nas expectativas das mulheres sobre elas mesmas, e nas expectativas do mundo sobre o lugar delas na sociedade". Seguindo o pensamento de Guiddens (1993), para Hobsbawn (1995) as mulheres não são as mesmas e esse foi um dos componentes mais importantes da revolução social e cultural do século XX. Porém,

Considerando que o Brasil foi colonizado por ocidentais, pode-se inferir que os homens brasileiros carregavam conceitos e valores, em relação à mulher, bem similares aos dos colonizadores. Portanto, a mulher no Brasil, historicamente, é vista sob o prisma da ideologia patriarcal. Ou seja, há, historicamente, em relação à mulher, uma exigência e imposição de docilidade, recato e submissão (Melo e Soeiro, 2020, p. 2).

Ribeiro (2018), ao analisar a categoria mulher negra chama a atenção para o fato de que as mulheres são oprimidas de forma diferenciada de acordo com a classe social e a raça e, por isso, o movimento feminista não se constituiu como uma voz integral, plena.

Em 1851, Sojourner Truth, ex-escrava que se tornou oradora, fez seu famoso discurso intitulado "eu não sou uma mulher?" na Convenção dos Direitos das Mulheres em Ohio. [...] ela já anunciava que a situação da mulher negra era radicalmente diferente da situação da mulher branca. Enquanto àquela época mulheres brancas lutavam pelo direito ao voto e ao trabalho, mulheres negras lutavam para ser consideradas pessoas (Ribeiro, 2018, p. 52).

Conforme a referida autora (2018, p. 45), a chamada terceira onda do movimento feminista, iniciada na década de 1990, enfatiza a necessidade de discutir gênero com recorte de classe e raça, pois a universalização da categoria mulher é excludente.

A tradição geográfica pela diferenciação espacial sempre indicou que as transformações sociais globais apresentam respostas distintas entre regióes em função das especificidades internas, conduzindo a uma organização espacial com temporalidades distintas. Se isso é fato, as transformações no papel da mulher na sociedade apresentam ritmos desiguais e, cabe a nós, nesse artigo, o olhar para a mulher espacialmente definida como rural.

Conforme Sales (2007), as discussões sobre a representação da mulher rural e sua importância nas esferas pública e privada chegam ao Brasil com mais representatividade somente a partir do ano de 1985, quase trinta anos depois das conquistas das mulheres urbanas. Para a autora, os direitos das mulheres no campo só puderam ser estabelecidos após a inserção da 'igualdade entre homem e mulher na família' proposta na Constituição de 1988. A mulher rural é, por essência, trabalhadora e tem suas atividades pautadas na subsistência da família tanto quanto o homem e, em determinados casos, ela é a provedora da família. Entretanto, as funções domésticas (os cuidados com a casa, com os filhos, com o marido) são obrigações históricas exclusivas, não superadas na pós-modernidade; a hierarquia de gênero e a consequente relação de autoridade/dependência está presente no espaço privado e no espaço público.

No Pantanal não é diferente, pois a paisagem rural contém as marcas do patriarcado. As mulheres pantaneiras moradoras das fazendas, independentemente da classe social e da raça, viveram a maior parte do tempo no universo da casa, desenvolvendo as chamadas atividades do 'lar', dependem dos maridos mesmo tendo salário ou ajudando nas atividades do homem.

Ao longo dos mais de 200 anos de ocupação regional, sem perceber claramente, a mulher pantaneira desempenhou atividades diretas e indiretas de suporte e sustentação da produção pecuária, sem nenhum tipo de remuneração ou direito trabalhistas, pois consideravam o trabalho exercido por elas como uma 'ajuda' 
aos maridos. Nesse sentido, é importante destacar os serviços femininos como essenciais no processo de desenvolvimento da atividade pecuária pantaneira.

Muitas iniciam o trabalho antes de clarear o dia, prepararam o quebra torto (uma espécie de café da manhã reforçado - preparado com café, mate, arroz, carne, mandioca, ovo, rapadura - para dar mais sustentação aos homens durante o período de trabalho no campo), fazem o almoço, limpam a casa e o entorno, lavam as roupas, cuidam das plantas e da criação doméstica (galinhas e porcos), produzem queijos, doces, linguiças, sabão, preparam o jantar, cuidam dos filhos.

O capital tem sabido também se apropriar intensificadamente da polivalência e multiatividade do trabalho feminino, da experiência que as mulheres trabalhadoras trazem das suas atividades realizadas na esfera do trabalho reprodutivo, do trabalho doméstico (Antunes, 2009, p. 109).

Em alguns casos, além das atividades descritas, as mulheres também são responsáveis pela limpeza e cuidados da casa principal. Outras estão diretamente ou indiretamente envolvidas com a atividade econômica e exercem funções pecuárias diversas, tais como: a contabilidade e administração das fazendas, o trabalho com o gado ou as viagens em comitivas (Figura 2).

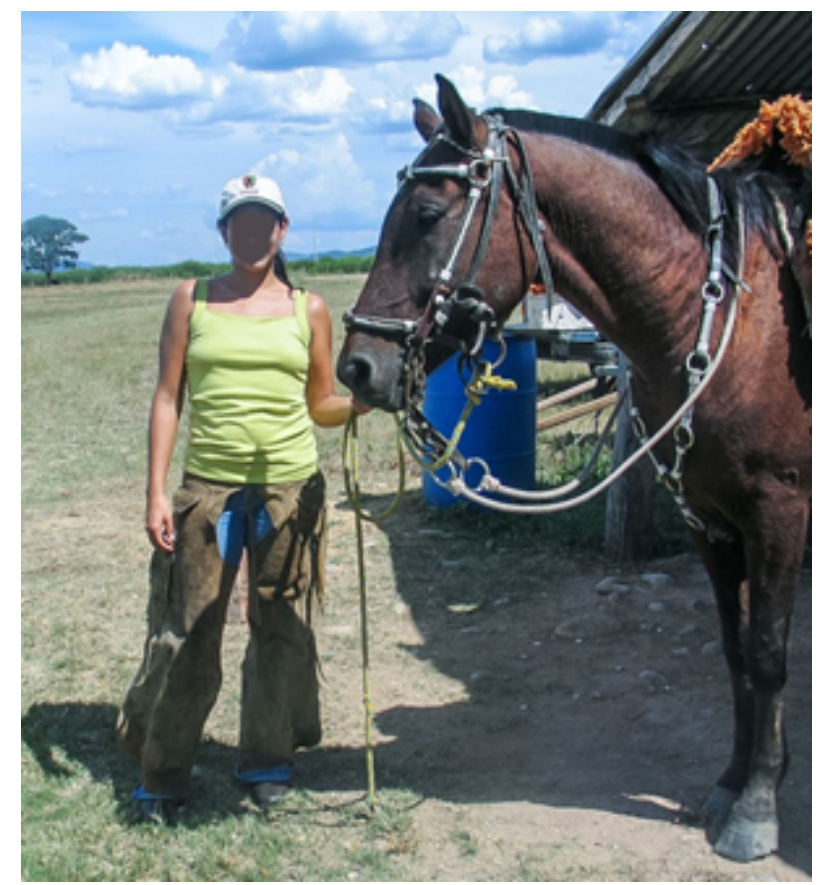

Figura 2: Mulher pantaneira trabalhadora da fazenda. Foto: Brum, E. (2018). Brum, E. (2018).

Com o turismo, a partir dos anos de 1980/1990, a mulher pantaneira se torna protagonista do setor, conduzindo a produção e a organização do espaço turístico regional, "[...] cabe destacar que esta mudança de caracterização do perfil profissional pouco muda na sua posição/participação dentro da família" (Lunardi, $R$. et al., 2016, p. 190). As fazendeiras, proprietárias rurais, assumem o planejamento, a gestão e a gerência da atividade, as demais assumem funções diversas dentro da divisão interna do trabalho: guias, recepcionistas, cozinheiras, camareiras, gerentes.

Contudo, há que se considerar que o turismo rural permite maior inserção das mulheres no mundo do trabalho produtivo e, consequentemente, maior valorização do trabalho feminino, ocasionando aumento da autoestima, melhoria da qualidade de vida, maior autonomia financeira, ampliação do ambiente de socialização (Lunardi, R. et al., 2015, p. 197).

Araújo (2006) destaca a importância da atividade na rentabilidade da propriedade, no incremento do número de empregos não agrícolas no espaço rural pantaneiro, retendo fluxo migratório e elevando a renda 
das famílias. Entretanto, conforme a autora, apesar do sucesso econômico, no universo relacional e simbólico a atividade é considerada secundária na estrutura econômico-produtiva do Pantanal.

A comunidade Passo da Lontra se insere no espaço turístico pantaneiro e as mulheres locais assumem o papel de destaque, exercendo as funções fundamentais no desenvolvimento da atividade.

O gráfico 1 revela o percentual das mulheres entrevistadas na delimitação espacial da pesquisa, por faixa etária.

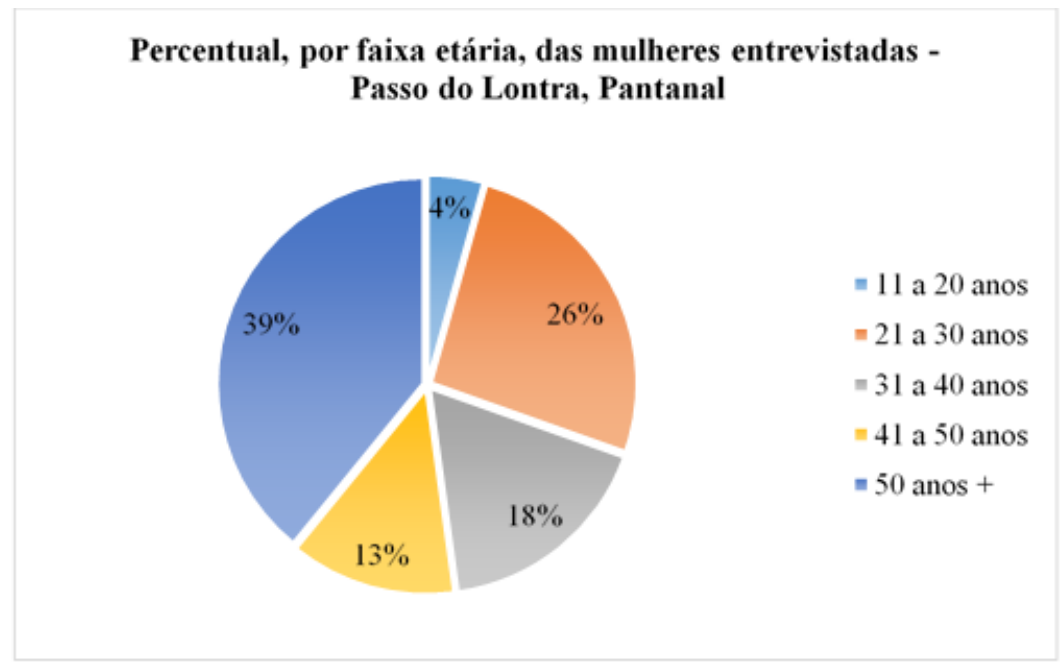

Gráfico 01: Percentual das mulheres entrevistadas na delimitação espacial da pesquisa. Fernandes, J. (2019).

A amostragem revela que 39\% das mulheres têm mais de 50 anos, trabalham na atividade turística como diaristas, camareiras e cozinheiras, fortalecendo a participação na renda familiar e desempenhando um novo papel na sociedade local. As mulheres mais jovens ocupam um percentual baixo porque optaram por morar nas cidades da Bacia do Alto Paraguai - BAP, para estudarem e trabalharem. Em algumas situações elas se casam e fixam residência distante da área do Pantanal. Porém, com o desemprego estrutural nas cidades, pode acontecer um retorno ao rural.

Como referido anteriormente, a inserção da região na globalização a partir de meados da década de 1990 , fomentou a entrada das mulheres pantaneiras no mercado de trabalho gerado pelo turismo; extrapolando o espaço da casa sem, contudo, abandonar o trabalho doméstico. Para Silveira e Medaglia (2016, p. 114), o "aumento da participação feminina no mercado não aliviou esse ônus doméstico e muito menos colocou em cheque a estrutura familiar patriarcal".

As mulheres do Passo da Lontra, passam a receber salários pelas atividades domésticas relacionadas ao trabalho turístico, mas os salários são significativos na composição da renda familiar.

A saída do espaço privado para o espaço público de vida e de trabalho contribuiu para a redução da natalidade, porém o número de filhos/as é superior à média nacional como mostra o gráfico 2. 


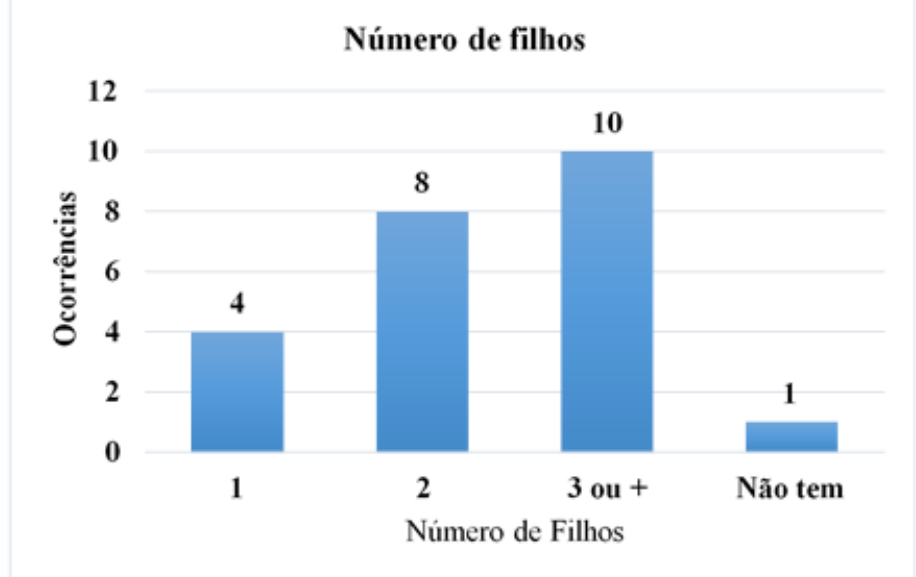

Gráfico 02: Número de filhos por mulher.

Fernandes, J. (2019).

Embora haja uma diminuição da natalidade brasileira em todas as regiões do país, na integralidade das entrevistadas, apenas uma não possui filhos/as. A média é de 3 filhos/as por pantaneira, apesar de acesso às políticas públicas e informações sobre métodos contraceptivos o número de filhos/as é superior à média nacional de 1,83 filhos/as por mulher (Soares e Schor, 2013). O atendimento à saúde na delimitação da pesquisa é precário, conta-se apenas com os Projetos de Extensão dos cursos de saúde da Universidade Federal de Mato Grosso do Sul, os quais doam contraceptivo para as mulheres. Porém os projetos são desenvolvidos no período letivo, comprometendo o uso sistemático de anticoncepcional, pois quando o medicamento termina não é possível adquiri-lo porque não tem farmácias no vilarejo. Nesses casos a mulher fica desprotegida e pode engravidar.

Outro aspecto sério da realidade rural brasileira é o baixo nível de escolaridade de sua população. Ao apresentar os dados sobre a escolaridade das mulheres pantaneiras, o gráfico 3 reafirma a posição negligenciada do espaço rural no acesso à educação, característica secular que os governos democráticos e os movimentos educacionais progressistas não conseguiram superar.

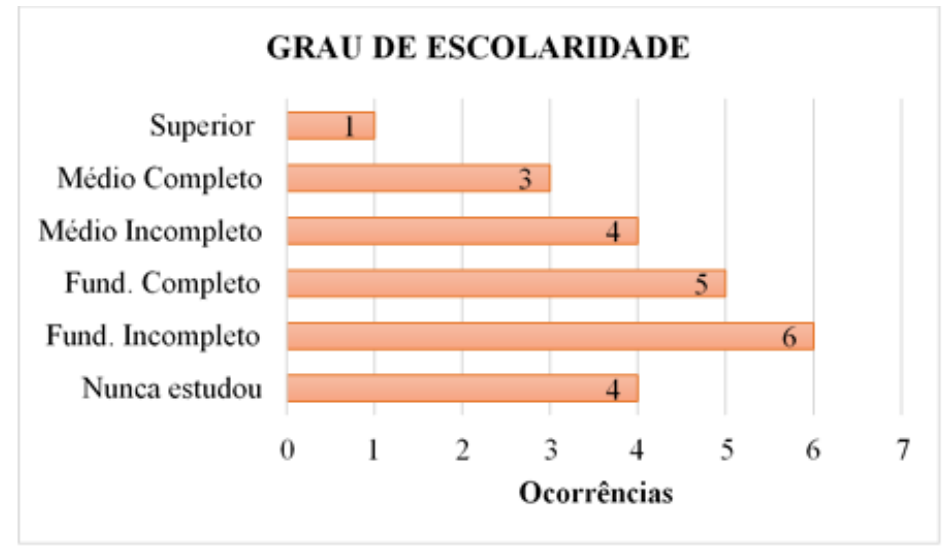

Gráfico 03: Grau de escolaridade.

Fernandes, J. (2019).

Do total de mulheres entrevistadas, apenas uma possui nível superior completo, a baixa escolaridade rural reafirma a incompetência da expansão acelerada e tardia do capitalismo no campo, a manutenção da posição periférica de um país rico em recursos naturais e a falta de planejamento territorial adequado. Aspectos que destroem qualquer possibilidade de reestruturação espacial e, ao mesmo tempo, comprometem a competição internacional do Pantanal como um espaço turístico. 
Terminado o Ensino Fundamental, a continuidade dos estudos fica prejudicada porque as famílias têm dificuldades em manter os filhos na escola, ao atingirem o Ensino Médio[2]. O estado, até o momento, não conta com unidade de ensino médio no Pantanal, tão pouco oferece condições para a fixação dos adolescentes pantaneiros na cidade, como por exemplo, alojamento de estudantes, para frequentarem as escolas urbanas (Ribeiro, 2015, p. 58).

Hobsbawm (1995, p. 295) afirma que "a revolução social atual tem como uma de suas características centrais a valorização da educação", notadamente da educação superior, que se expande quantitativamente nos países hegemônicos e não hegemônicos, com expressiva explosão do número de estudantes. Para Harvey (1994, p. 143), “[..] essa nova dinâmica social está vinculada à reestruturação do mercado de trabalho, mais disputado e flexível”. Na competição internacional, a qualificação da mão de obra é essencial.

A capacidade de obter êxito nas ações propostas e o futuro da atividade dependerá das metas, da qualidade dos serviços prestados e da capacidade dos empreendedores em conduzir os seus negócios considerando, entre vários outros aspectos, a capacitação e o treinamento próprios e das suas equipes (Ruschmann e Solha, 2004, p. 05).

$\mathrm{Na}$ contramão do desenvolvimento, o Brasil é um país 'pouco educado'; essa não é uma realidade apenas do rural, embora se acentue nesse espaço. Segundo dados do IBGE (2010), 43,4 \% da população brasileira tem ensino fundamental incompleto ou não tem instrução, o que pode justificar a expressiva ocorrência da resposta 'nunca estudou'. Embora seja um direito previsto na Constituição brasileira de 1988, a falta de Educação formal é um problema estrutural que contribui significativamente para a manutenção da posição de dependência do país no sistema mundo.

Apesar das transformações espaciais e econômicas iniciadas a partir da década de 1930, com a implementação do modelo urbano-industrial, a modernização que ocorreu no país foi conservadora, pois as estruturas sociais precarizadas foram mantidas. Essa opção manteve o país na condição de periferia econômica do mundo definida pelo desenvolvimento desigual e combinado dentro da lógica integração e diferenciação de áreas imposta pelo capitalismo mundial (Becker e Egler, 1993). O Brasil preservou-se opaco e, por conseguinte, permanece marginal ao processo (Santos, 1988).

Como consequência, na articulação regional-global, a exuberância da paisagem natural e cultural pantaneira não é suficiente para a competição do produto turístico Pantanal. Na tentativa de minimizar esse embate, o governo do estado de Mato Grosso do Sul, em parceria com a iniciativa privada, promoveu cursos de capacitação profissional na área do turismo, com o objetivo de treinar trabalhadores/as em práticas hoteleiras, do atendimento ao gerenciamento, passando pelo agenciamento.

No território turístico do Passo da Lontra, o trabalho voltado às mulheres é dividido em dois grupos articulados: os vinculados diretamente ao turismo e os de apoio. Faz-se necessária a inclusão da palavra 'diretamente' ao se tratar da prestação de serviços (camareira, cozinheira, etc.), uma vez que algumas atividades praticadas por esse segundo grupo (babás, comerciantes, etc.) têm relação indireta com o turismo. Trata-se de um trabalho flexível de baixa remuneração. Segundo as entrevistadas, o pagamento mensal está referenciado no salário mínimo, mas é importante considerar que $70 \%$ delas trabalham no sistema de diárias e estão sujeitas às variações de baixa e alta temporada. Na tentativa de fazer uma análise científica, foi ponderado entre os/as pesquisadores/as o ideal imaginário que permeou as respostas e um possível constrangimento em expressar a realidade econômica.

A remuneração semanal ou diária pelos serviços prestados não caracterizava vínculo empregatício, deixando a trabalhadora sem proteção dos direitos trabalhistas, em consequência, há muita rotatividade de emprego, na busca por melhores condições de trabalho e de remuneração (Ribeiro, 2015, p.54).

As mulheres que não possuem atividades ligadas diretamente ao turismo trabalham em setores de comércio e serviços, como comerciantes, vendedoras ambulantes, babás e funcionárias terceirizadas da Base de Estudos do Pantanal da Universidade Federal de Mato Grosso do Sul - UFMS, localizada próxima à comunidade.

Para compreender o sentimento de pertença e de identidade, apontado por Vargas (2006) como necessário na construção identitária e no desenvolvimento de territorialidades no espaço rural, questionamentos do tipo 
"O que o Pantanal significa para você?", "Como é morar no Pantanal?", "Você se identifica como pantaneira?" e "o que é ser mulher?”, fizeram parte do roteiro da entrevista. As respostas dão luzes às percepções do idílico e a dimensão imaterial do território ao apresentar-se nas respostas com um significado pessoal do viver pantaneiro como: "Maravilhoso", "Um sonho", "Paz e tranquilidade", "Sou pantaneira com orgulho"; fica perceptível nas falas o caráter hipotético das respostas, da fantasiosa representação do feminino em um Pantanal cheio de contrastes e contradições.

O território, sendo formado de partes indissociáveis do material e do imaterial, do funcional e do simbólico (Araújo e Haesbaert, 2007), contém representações expressas no discurso de perfeição do local, transformados em sentimento de identidade e pertencimento ao lugar.

A funcionalidade territorial em questão é também expressa no discurso das mulheres pantaneiras. As respostas aos questionamentos sobre "o que é ser mulher" e "como é ser mulher no Pantanal" revelam o trabalho aguerrido: "batalhadeira", "guerreira", "lutadora". Essas vozes carregam o sentido e o significado simbólico do Pantanal, uma região de difícil acesso, de convivência com o ciclo das águas que imprime períodos de cheia e seca e exigem adaptabilidade e perseverança. A luta, o desafio, a conquista, antes marcas da identidade do homem pantaneiro, passam a ser incorporadas ao feminino, em uma construção identitária referenciada na internalização, na autoconstrução e na individualização, organizando significados para o indivíduo e para o grupo social.

Essa dinâmica, obviamente, não é harmoniosa e - como carrega a dimensão simbólica - não é, tampouco, visível. A estruturação de identidades se faz mediante disputas constantes, um verdadeiro campo de batalha.

Identidade, sempre que se ouvir esta palavra, pode-se estar certo de que está havendo uma batalha. O campo de batalha é o lar natural da identidade. Ela só vem a luz no tumulto da batalha, e dorme e silencia no momento em que desaparecem os ruídos da refrega [...]. A identidade é uma luta simultânea contra a dissolução e fragmentação; uma intenção de devorar e ao mesmo tempo uma recusa absoluta de ser devorado (Bauman, 2005, p.83).

O Pantanal por elas é a representação da luta pela afirmação da identidade enquanto forma de reconhecimento social da diferença. O poder de definir e marcar a diferença é, segundo Silva (2004), inseparável das relações mais amplas de poder. Para este autor, a identidade e a diferença não são, nunca, inocentes, e servem tanto para a manutenção e legitimação das relações de poder hegemônicas da sociedade, quanto para subvertê-las.

Sabe-se que no Pantanal e no mundo, a desigualdade de gênero continua existindo apesar dos avanços. Segundo Delphy, (1999 como citado em Trat, 2014, p. 369) "um dos indicativos da manutenção da opressão das mulheres ocorre nas relações domésticas em função da exploração gratuita do trabalho na casa". Para Guiddens (2002, p. 247), "a multifuncionalidade associada à mulher e a responsabilidade assumida por ela não substituiu ou dividiu o trabalho doméstico", as funções foram adicionadas, incidindo na questão da desigualdade salarial entre homens e mulheres. Porém, as mulheres não são as mesmas, e isso é universal, as transformações nas representações do feminino provocaram rupturas sociais, destituíram concepções estruturadas e estruturantes e provocaram a revolução na intimidade e nos espaços de poder.

\section{Considerações (não) Finais}

Historicamente, no Pantanal a participação da mulher nas atividades econômicas gira em torno das funções domésticas. Com a inserção da atividade turística e do trabalho remunerado nas últimas décadas do século XX, iniciou um processo de fortalecimento da representação feminina como protagonista local e de estruturação de uma identidade da mulher pantaneira, entretanto sem alterar a característica do trabalho. O emprego gerado pela atividade é flexível, de baixa remuneração e voltado para as atividades de limpeza, cozinha e cuidados gerais. 
A tríade idade, maternidade e escolaridade cartografaram o perfil da mulher pantaneira moradora da comunidade do Passo da Lontra, em construção e reconstrução desde a primeira metade do século passado e reorganizada a partir do início da atividade turística.

Assim, os estudos e as análises apresentadas no texto sobre as atividades femininas no Pantanal de hoje abrem um leque de opções dos contributos da mulher na organização territorial e fundiária pantaneira. Ainda que seja um viver no mundo rural, a mulher do Passo da Lontra exprime características cotidianas urbana, imprimindo territorialidades sui generis a essa comunidade.

O movimento feminino no espaço pantaneiro impõe a presença da multifuncionalidade e da reprodução dos papéis domésticos a serviço de uma atividade econômica - o turismo, caracterizando ascensão no estrato social e melhoria nas condições de vida, a partir do desempenho de funções relevantes, mesmo que de baixa remuneração, para a manutenção do Pantanal na engrenagem econômica mundial, pois dão suporte para o incremento do turismo e da pecuária de corte.

Parece paradoxal, mas, realmente, a mulher pantaneira trabalhadora do turismo ainda desenvolve atividades tradicionalmente ligadas ao feminino, os postos de serviço a elas atribuídos são, sobretudo, de camareiras, cozinheiras e nos serviços gerais, a despeito de os homens também poderem exercer essas atividades. Nesse universo, as mulheres que tiveram oportunidade de fazer um curso de qualificação profissional ou graduação ocupam os cargos de gerência nas pousadas, porém, é comum encontrá-las acumulando funções, entre a administração e o atendimento direto aos/às turistas ou substituindo alguém na equipe de cozinha.

A discussão desenvolvida no artigo permitiu atingir o objetivo principal, de analisar o papel da mulher na produção do espaço turístico pantaneiro a partir do referencial teórico proposto; tendo - nas diversas mulheres e nos distintos papéis a elas atribuídos - a carga cultural e indenitária que produz historicamente os territórios e engendram territorialidades no espaço pantaneiro, emoldurando paisagens rurais de luta.

Assim, entre cheias e vazantes, ipês e caraguatás, mosquitos e onças, as mulheres pantaneiras produzem um Pantanal feminino com todo esplendor e exuberância.

\section{REFERÊNCIAS}

Antunes, R. (2009). Os sentidos do trabalho: ensaios sobre a afirmação e a negação do trabalho. (2a ed., 10a. reimpressão, revisada e ampliada). Boitempo.

Araújo, A. P. C. (2006). Pantanal: um espaço em transformação. .Tese de Doutorado, PPGG/UFRJ]. Biblioteca Digital UFRJ. http://http//www.ppgg.igeo.ufrj.br/

Araújo, A. P. C. \& Bicalho, A. M. de S. M. (2010). O rural em movimento. EdUFMS.

Araújo, F. G. B. \& Haesbart, R. (Orgs.). (2007). Identidades e territórios: questões e olhares contemporâneos. Access. Bauman, Z. (2005). Identidade. Zahar.

Becker, B. K. \& Egler, C. (1993). Brasil: uma nova potência regional na economia - mundo. Bertrand Brasil.

Biasoli-Alves, Z. M. M. (2000). Continuidades e rupturas no papel da mulher brasileira no século XX. Revista Psicologia: teoria e pesquisa, 16(3), 233-239. https://www.scielo.br/scielo.php?pid=S0102/=pt

Brum, E. (2018). Mulher pantaneira trabalhadora da fazenda. Figura 02. Acervo particular.

Castells, M. (1999). O poder da identidade. Paz e Terra.

Esselin, P. M. \& Oliveira, T. C. M. (Orgs.). (2012). Fronteiras Esquecidas: a construção de hegemonias nas fronteiras entre os rios Paraguai e Paraná. EdUFGD.

Fernandes, J. F. A. (2019). Gráficos 01, 02, 03. Acervo particular.

Giddens, A. (1993). A transformação da intimidade. EdUnesp.

Giddens, A. (2005). Sociologia. Artmed.

Gil, A. C. (2011). Métodos e técnicas de pesquisa social. (6a ed.). São Paulo: Atlas. 
Hall, S. (2004). Quem precisa de identidade? In: T. T. Silva. (Org.). Identidade e diferença: a perspectiva dos estudos culturais. (pp. 103 - 133). Vozes.

Harvey, D. (1994). Condição pós-moderna. Loyola.

Hobsbawm, E. (1995). A era dos extremos. Companhia das Letras.

Instituto Brasileiro de Geografia e Estatística. (2010). Censo demográfico. http://www.ibge.gov.br/apps/arranjos-po pulacionais/2016/pdf/

Instituto Brasileiro de Geografia e Estatística. (2020). Delimitação do Pantanal. http://www.ibge.gov.br/

Lunardi, R. et al. (2016). O trabalho de homens e mulheres no turismo rural em São José dos Ausentes: o "leve" e o "pesado". Revista Turismo - Visão e Ação, 17(1), 179-209. https://siaiap32.univali.br/seer/index.php/rtva/ar ticle/view/17001

Melo, G. P. F. S. \& Soeiro, Í. C. M. (2020). A mulher e o deslocamento turístico no mundo contemporâneo: uma contribuição teórico-metodológica aos estudos do turismo. Caderno Virtual de Turismo, 20(2), 1-12. http://w ww.ivt.coppe.ufrj.br/caderno/index.php/caderno/article/view/1764

Queiroz, D. T. et al. (2007). Observação participante na pesquisa qualitativa: conceitos e aplicações. Revista Enfermagem, 15(2), 276-283. https://pesquisa.bvsalud.org/portal/resource/pt/bde-14792/

Ribeiro, D. (2018). Quem tem medo do feminismo negro? Companhia das Letras.

Ribeiro, M. A. (2015). Entre cheias e vazantes: a produção de geografias no Pantanal. EdUFMS.

Ruschmann, D. \& Solha, K. T. (2004). Turismo: uma visão empresarial. Manole.

Sales, C. M. V. (2007). Mulheres rurais: tecendo novas relações e reconhecendo direitos. Revista Estudos Feministas, 15(2), 437-443. https://periodicos.ufsc.br/index.php/ref/article/

Santos, M. (1988). Metamorfose do espaço habitado. HUCITEC.

Silva, J. S. V. \& Abdon, M. M. (1998). Delimitação do Pantanal brasileiro e suas sub-regióes. Revista Pesquisa Agropecuária Brasileira, 33(13), 1703-1711. https://seer.sct.embrapa.br/index.php/pab/article/view/5050/72 03

Silva, T. T. (2004). A produção social da identidade e da diferença. In: T. T. Silva. (Org.). Identidade e diferença: a perspectiva dos estudos culturais. (pp. 73 - 102). Vozes.

Silveira, C. A. \& Medaglia, J. (2016). Relações entre gênero e mercado de trabalho de turismólogos em Minas Gerais. Caderno Virtual de Turismo, 16 (1), p.109-125. http://www.ivt.coppe.ufrj.br/caderno/index.php /caderno/article/view/1044

Soares, V. M. N. \& Schor, N. (2013). Perfil de mulheres com alta fecundidade em um grande centro urbano no Brasil. Ciência \& Saúde Coletiva, 18(4), 1041-1050. https://www.scielo.br/pdf/csc/v18n4/17.pdf

Trat, J. (2014). Freidrich Engels: da propriedade privada à sujeição da mulher. In: D. Chabaud-Rychter, V. Descoutures \& E. Varikas. (Orgs.). O gênero nas ciências sociais. (pp. 359 - 372). EdUNB.

Tomas, W. M. et al. (2019). Sustainability agenda for the Pantanal wetland: perspectives on a collaborative interface for science, policy, and decision-making. Tropical Conservation Science, 12, 1-30. https://journals.sagepub.co $\mathrm{m} / \mathrm{doi} / 10.1177 /$

Vargas, I. A. (2006). Território, identidade, paisagem e governança no Pantanal Mato-grossense: um caleidoscópio da sustentabilidade complexa. [Tese de Doutorado, PPGMADE/UFPR]. Biblioteca Digital UFPR. http://www. ppgmade.ufpr.br/

\section{Notas}

[1] Referência às mulheres que vivem e produzem no Pantanal, independente da naturalidade e da nacionalidade.

[2] O ensino médio é de reponsabilidade do governo do Estado de Mato Grosso do Sul. 